\title{
Terminology of chronic pain: the need to "level the playing field"
}

\author{
This article was published in the following Dove Press journal: \\ Journal of Pain Research \\ 27 January 2016 \\ Number of times this article has been viewed
}

\author{
John F Peppin' \\ Michael E Schatman ${ }^{2}$ \\ 'Center for Bioethics, Pain \\ Management and Medicine, St Louis, \\ MO, ${ }^{2}$ US Pain Foundation, Middletown, \\ CT, USA
}

\section{Discussion}

Pain medicine as a separate subspecialty is in its infancy, only fairly recently being recognized as such by the American Board of Medical Specialities. ${ }^{1}$ As it continues to find its way in the ever-changing world of medicine, terminology becomes an important consideration. Terms carry tremendous impact: for example, when a patient is told he or she has "cancer", the impact emotionally will undoubtedly make further explanation difficult. To patients and their families, the word "cancer" has the effect of being hit with an emotional baseball bat. In the pain world, there was a recent, albeit failed, attempt to change the name of pain specialists to "algiatrists". ${ }^{2}$ It was thought this would help define what such specialists did as opposed to other specialties. Accordingly, terminology matters, yet little attention has been paid to the terms we use to categorize and diagnose our patients. "Chronic cancer pain" and "chronic noncancer pain" are replete in the literature; however, the distinction here is actually obscure. A patient with pain from a cancer etiology has no different physiology than a patient with pain of noncancer etiologies.

Much of the development in the literature defining these two different categories came from the move in the 1990s to change the way chronic pain in patients without cancer was treated..$^{3}$ It was postulated that if opioids worked for pain in cancer patients, then we should accordingly use these same agents in those with pain not related to cancer. Further, it was posited that these patients were suffering, and opioids were one more tool to help ease their suffering. Those using the term "chronic noncancer pain" were in two camps: those who felt that opioids should be avoided in patients without cancer, and those who felt they were yet one more tool for the treatment of these patients. ${ }^{3,4}$

Interestingly, these claims are primarily philosophical, rather than medical or physiologic. As mentioned, pain mechanisms do not discriminate between cancer and noncancer pathophysiology. Patients with cancer or those without cancer have essentially identical pain-generating physiologies, and thus the same mechanisms for the development of their pain (eg, inflammatory pain in a cancer patient will be the same physiological process as in a noncancer patient). Further, cancer patients are living longer and their original pain generators become chronic pain in and of themselves, little different from patients without cancer. Frequently, the claim is that those without cancer should not have to undergo the side effects of opioids, and they should not have to take on the potential burden of iatrogenic addiction. Furthermore, they note that there are
Center for Bioethics, Pain Management and Medicine, 8013 Presidio Court, University City, St Louis, MO 63130, USA Email johnpeppin@msn.com 
few data to support opioid use in these patients. Interestingly, the data on the use of opioids in cancer patients suffer from the same criticism, lack of long-term data, and lack of data demonstrating increased functionality. ${ }^{5,6}$ However, there is frequently the caveat that those with cancer should receive opioids, which represents a rather strange dichotomy. This line of reasoning can be interpreted as follows:

1. We do not care if the patient with cancer suffers from side effects, fatal or otherwise from opioids, and/or develops a substance-use disorder. But we do care if a patient with chronic "noncancer" pain develops these problems.

2. We do not care if patients with noncancer pain suffer; they are not "worth" the effort of adding opioids to their regimens.

The purpose of this commentary is not to develop a foundation for increased use of opioids, nor are we suggesting that opioids be used more in patients without cancer. However, a thorough evaluation, followed by a clear delineation of the pain generators, will help define potential treatments, which may (or may not) include opioids. This should not be based on philosophical biases, or at least those biases should be stated openly up front as having no scientific foundation. Obviously, given other considerations associated with initiating chronic opioid therapy and the need for continued reevaluation, opioids may not be the best option. However, simply the label of "chronic noncancer pain" should not immediately place that patient in a category that eliminates certain potential therapies, eg, opioids.

Therefore, we suggest that the terminology be changed to help us better to understand and treat all of our chronic pain patients who are suffering. Categorization into "cancer" and "noncancer" does not help us better understand mechanisms underlying pain or guide us to appropriate treatment strategies. Further, these categories are philosophical and neither scientific nor of clinical relevance. Perhaps a more prudent, less charged set of terms would indicate the origin and generator of the pain. Therefore, a patient with chest-wall pain from radiation due to breast cancer would be labeled "chronic pain of breast cancer radiation-treatment origin". The patient with pain from an advanced spondylolisthesis would be diagnosed with "chronic pain of spondylolisthesis origin". The goal here is to continue to be patient-focused, relieve their suffering (instead of contributing to it), and help improve their lives. Language, in and by itself, is obviously not a "cure" for pain. However, clinicians and society as a whole need to appreciate language's potential to further stigmatize and marginalize all patients suffering from chronic pain, and accordingly we are obliged to work toward a more language-neutral system of pain classification.

\section{Disclosure}

The authors report no conflicts of interest in this work.

\section{References}

1. American Board of Pain Medicine. What is pain medicine? Definition of pain medicine. Available from: http://www.abpm.org/what. Accessed December 4, 2015

2. American Board of Medical Specialties. Specialty and subspecialty certificates. Available from: http://www.abms.org/member-boards/ specialty-subspecialty-certificates. Accessed October 27, 2015.

3. Portenoy RK. Chronic opioid therapy in nonmalignant pain. J Pain Symptom Manage. 1990;5(1 Suppl):S46-S62.

4. Von Korff M, Deyo RA. Potent opioids for chronic musculoskeletal pain: flying blind? Pain. 2004;109(3):207-209.

5. Koyyalagunta D, Bruera E, Solanki DR, et al. A systematic review of randomized trials on the effectiveness of opioids for cancer pain. Pain Physician. 2012;15(3 Suppl):ES39-ES58.

6. Mesgarpour, B, Griebler U, Glechner A, et al. Extended-release opioids in the management of cancer pain: a systematic review of efficacy and safety. Eur J Pain. 2014;18(5):605-616.
Journal of Pain Research

\section{Publish your work in this journal}

The Journal of Pain Research is an international, peer-reviewed, open access, online journal that welcomes laboratory and clinical findings in the fields of pain research and the prevention and management of pain. Original research, reviews, symposium reports, hypothesis formation and commentaries are all considered for publication.

\section{Dovepress}

The manuscript management system is completely online and includes a very quick and fair peer-review system, which is all easy to use. Visit http://www.dovepress.com/testimonials.php to read real quotes from published authors. 